\title{
Key Regulators of Sucrose Accumulation during Different Developmental Phases of Sugar Beet Plants
}

\author{
Awatif S. Ali \\ Botany Department, Faculty of Science, Kafrelsheikh University, Kafr El-Sheikh, \\ Egypt.
}

\begin{abstract}
B ECAUSE of the economic importance of sugar beet (Beta vulgaris L) in sucrose production, a field experiment was conducted to elucidate the key regulators of sucrose metabolism in source leaves and sink roots at 135, 150, 165 and 180 day after sowing (DAS) that would be determined sucrose yield. Increase in sucrose phosphate synthase (SPS) activity in source and sink tissues during the first three selected harvest phases was associated in leaves with an increase in activities of acid invertase (AI) and neutral invertase (NI), chlorophyll a, total chlorophyll and reducing sugars on the one hand and the levels of sucrose and inorganic phosphorus $\left(\mathrm{P}_{\mathrm{i}}\right)$ in roots on the other hand. The maximum sucrose level in roots was at 165 DAS. A gradual increase in root NI activity accompanied by an increase in reducing sugars and a decrease in the sucrose/reducing sugars ratio in roots by harvest date progress was observed. Pearson correlation test revealed contradictory findings whereas, SPS activity correlated with sucrose level in leaves negatively but positively in roots. All investigated enzymes in leaves correlated negatively with sucrose/reducing ratio. In roots, only NI activity correlated negatively with sucrose/reducing sugars ratio.
\end{abstract}

Keywords: AI activity, $\mathrm{Chl}$ b/Chl a ratio, $\mathrm{P}_{\mathrm{i}}$ level, SPS activity, Sucrose/reducing sugars ratio.

\section{Introduction}

Sucrose transport from source photosynthetic tissues to sink tissues is largely variable with cell physiological statue and developmental phase that could be considered as a potent regulator in carbon partitioning, plant growth and productivity (Gupta, 2006). Photosynthetic triose-phosphate product can be funneled into starch biosynthesis in the chloroplast or effluxed via triose-phosphate translocator (TPT) on the chloroplast inner membrane to cytosol where it is directed into sucrose biosynthesis. Sucrose exported to sink organs to be utilized in growth and development and/or in structural and storage functions of the plant cell (Hess \& Willmitzer, 1996).

SPS catalyzes the formation of sucrose6-phosphate in the second step of sucrose biosynthesis pathway from UDP-Glucose and Fructose-6-phosphate in the cytosol (Stitt \& Quick, 1989). Eventually, sucrose phosphate phosphatase activity triggered irreversible hydrolysis of sucrose-6-phosphate to generate sucrose (Jaleel et al., 2007). Either of glucose-6-phosphate as activator or $\mathrm{P}_{\mathrm{i}}$ as inhibitor by allosteric modulation can control SPS activity through regulation of phosphorylation/dephosphorylation (McMichael et al., 1995). However, $P_{i}$ is an essential element in the biochemical transitions through provoking highly energetic bonds in molecules of ATP and $\mathrm{ADP}$, in the structure of certain biomolecules and membranes, and as an integral component of many metabolic reactions and signal transduction pathways (Ticconi et al., 2001). In addition, $P_{i}$ deficiency severely declined the photosynthetic rate, induced starch accumulation at the expense of sucrose and modulated the activity of many key photosynthetic enzymes (Rao et al., 1989).

Endler et al. (2006) reported that sucrose accumulation-inhibited photosynthesis assigned to repression of gene expression of photosynthesis. Degradation of sucrose is contributed to activity of each of sucrose synthase and invertases enzymes which can determine sink strength (Moscatello et al., 2011). However, invertases maintain the source balance by catalyzing irreversible hydrolysis of sucrose into glucose and fructose and hence, regulate sugar composition and metabolic fluxes (Geromel et al., 2006). Distribution of sucrose metabolism intermediates 
including glucose-6-phosphate, fructose-6phospahte, glucose, fructose and UDP-glucose was suggested to regulate cell wall biosynthesis, starch synthesis and other metabolic activities such as maintaining cell division and embryo growth in various plants (Kutschera \& Heiderich, 2002 and Borisjuk et al., 2003). Based on subcellular localization, enzyme $\mathrm{pH}$ optimization and relative isoelectric points; invertases were classified into acid invertases which localized on cell wall and inside the vacuole ( $\mathrm{pH} 4.5-5.5)$ and neutral/alkaline invertases which localized in the cytosol $(\mathrm{pH}$ from 7 to 7.8 ) (Lee \& Sturm, 1996).

This study is aimed to investigate regulation of sucrose accumulation in source and sink tissues of sugar beet plants at latest developmental stages that could be a determinant for sucrose yield. The changes in activities of SPS, AI and NI, together with the variation in chlorophyll fractions, reducing sugars content, sucrose/reducing sugars ratio and $\mathrm{P}_{\mathrm{i}}$ levels were investigated in leaves as well as in roots. In addition, Pearson correlation test was conducted to elucidate the strength of the relation between sucrose accumulation and each of the studied parameters.

\section{Materials and Methods}

\section{Materials}

UDP-glucose, fructose-6-phosphate and glucose-6-phosphate were purchased from Sigma Chemical Co (via Egyptian center, Cairo, Egypt). Plant analysis was carried out at Botany Department, Faculty of Science, Kafr El-Sheikh University.

\section{Plant Material}

Sugar beet seeds were sown on $1^{\text {st }}$ October /2016 in clay soil prepared according to agricultural practices previously recommended by Ministry of Agriculture at a private farm, Matbol Village, Kafr El-Sheikh Province, Kafer El-Sheikh Governorate, Egypt. Plants were grown under environmental conditions (photoperiod of $16 \mathrm{~h} / 8 \mathrm{~h}$ light/dark, $23.6 / 12.4^{\circ} \mathrm{C}$ light/dark temperature average). Plants of 30d-old were thinned to one plant/hill, and then supplied with urea as a source nitrogen fertilizer on two equal doses (80kg urea/fad); $1^{\text {st }}$ dose after thinning and $2^{\text {nd }}$ one was month later. Soil phosphorus fertilization was prepared by adding $15 \mathrm{~kg}$ of calcium super phosphate $\left(15 \% \mathrm{P}_{2} \mathrm{O}_{5}\right) / \mathrm{fad}$. Leaves and roots samples for biochemical analysis each at three replicates were harvested on clear sunny days at different growth stages; 135, 150, 165 and 180DAS. Samples were collected from youngest three full expanded leaves and from the middle root core and immediately frozen in liquid $\mathrm{N}_{2}$ and kept in deep freezer to be used.

\section{Biochemical analysis}

Determination of sucrose (Suc) content

As described by Buysse \& Merckx (1993); sucrose content was determined by degrading reactive sugars present in $0.1 \mathrm{ml}$ alcoholic extract with $0.1 \mathrm{ml}$ of $5.4 \mathrm{~N} \mathrm{KOH}$ at $97^{\circ} \mathrm{C}$ for $10 \mathrm{~min}$. Then, $3 \mathrm{ml}$ of freshly prepared anthrone reagent $\left(0.15 \%\right.$ in $\left.70 \% \mathrm{v} / \mathrm{v} \mathrm{H}_{2} \mathrm{SO}_{4}\right)$ were added to the cooled reaction product, heated at $97^{\circ} \mathrm{C}$ for $5 \mathrm{~min}$, cooled and absorbance was read at $620 \mathrm{~nm}$ using a spectrophotometer. Sucrose concentration was obtained by using of a calibration curve.

\section{Determination of chlorophyll (Chl) content}

Chlorophyll extract of sugar beet leaves in $80 \%$ acetone was measured immediately spectophotomerically at 664, 648 and 470nm. Concentrations of $\mathrm{Chl}$ a and $\mathrm{Chl} b$ were calculated according to Lichtenthaler (1987).

Determination of reducing sugars (Red sugars)

The dinitrosalicylic acid method (Miller, 1959) was applied for reducing sugars determination. A standard curve of glucose is used in calculation of reducing sugars concentration.

Extraction and assay of SPS (EC 2.4.1.14) activity

Frozen leaf and root sugar beet samples $(0.5 \mathrm{~g})$ were ground in a liquid $\mathrm{N}_{2}$ to powder and extracted with $4 \mathrm{ml}$ extraction buffer [containing 50mM HEPES-KOH pH 7.5, 1mM EDTA, $10 \mathrm{mM} \mathrm{MgCl}_{2}, 2 \mathrm{mM}$ DTT (dithiothreitol), $1 \mathrm{mM}$ PMSF (phenylmethylsulphonyl fluoride), $0.1 \%$ TritonX-100, and 10\% (v/v) glycerol, $1 \mathrm{mM}$ benzamidine]. Homogenized samples were transferred into pre-chilled centrifuge tubes and spun at $12000 \mathrm{~g}$ for $15 \mathrm{~min}$ at $4^{\circ} \mathrm{C}$. Eventually, the supernatant is dialyzed against extraction buffer minus Triton X-100 and glycerol overnight. SPS extract was used immediately for enzyme assay as described by Chen et al. (2001). Reaction mixture including enzyme extract of $70 \mu \mathrm{l}$ final volume containing $3 \mathrm{mM}$ UDP-glucose, $4 \mathrm{mM}$ fructose6-P, 20mM glucose-6-P, $5 \mathrm{mM} \mathrm{MgCl}_{2}$ and $1 \mathrm{mM}$ EDTA was incubated at $37^{\circ} \mathrm{C}$ for $20 \mathrm{~min}$. The reaction was terminated by adding $70 \mu 1$ of $5.4 \mathrm{~N}$ $\mathrm{KOH}$ to destroy unreacted hexose phosphate, 
heated to $95^{\circ} \mathrm{C}$ for $10 \mathrm{~min}$, centrifuged at $12000 \mathrm{~g}$ for $5 \mathrm{~min}$ at $4^{\circ} \mathrm{C}$ and absorbance was measured at $620 \mathrm{~nm}$ after adding $1 \mathrm{ml}$ of $15 \%$ anthrone reagent. Protein content was determined by using Bradford (1976) method.

Extraction and assay of AI and NI (EC 3.2.1.26) activities

Invertases were extracted by using procedure of Oliveira et al. (2006). Activities of AI and NI were assayed following the methods of Jaleel et al. (2007) and Wongmetha et al. (2012). A reaction mixture of $900 \mu \mathrm{l}$ contained $200 \mathrm{mM}$ citrate phosphate $(\mathrm{pH} 4.5$ for $\mathrm{AI}$ and $\mathrm{pH} 7$ for NI activity), 200mM sucrose, 200mM Na $\mathrm{HPO}_{4}$ incubated with $100 \mu$ l of desalted enzyme extract at $37^{\circ} \mathrm{C}$. The reaction was stopped at 0 and $60 \mathrm{~min}$ by adding $1 \mathrm{ml}$ of DNS reagent to determine the released reducing sugars (Miller, 1959), boiling for $5 \mathrm{~min}$ and after cooling the absorbance was read at $540 \mathrm{~nm}$.

Extraction and measurement of $P_{i}$ content

According to the method of Ye et al. (2015), samples of $0.5 \mathrm{~g}$ frozen dried leaves and roots of sugar beet plants were ground in $4 \mathrm{ml}$ of $5 \%(\mathrm{v} / \mathrm{v}) \mathrm{HClO}_{4}(\mathrm{v} / \mathrm{v})$. The homogenate was centrifuged at $12000 \mathrm{~g}$ for $20 \mathrm{~min}$ and the pellets were re-extracted again in $1 \mathrm{ml}$ of $5 \%$ perchloric acid and centrifuged. The two supernatants were collected and kept for using in $\mathrm{P}_{\mathrm{i}}$ determination. The process of extraction was carried out at $4^{\circ} \mathrm{C}$. $\mathrm{P}_{\mathrm{i}}$ concentration was detected by molybdate-blue colorimetric method of Chen et al. (1956) at the absorbance of $820 \mathrm{~nm}$.

\section{Statistical analysis}

Triplicates of all tested variants were analyzed statistically using IBM SPSS statistic version 22 software. Means and standard errors of variants were elaborated. To evaluate which means were

TABLE 1. Changes in chlorophyll fractions content in leaves of sugar beet plants during different developmental phases. significantly different at $\mathrm{P} \leq 0.05$; One-way ANOVA for variance test, least significant difference (LSD) was conducted. To assign any correlations of sucrose levels either in source leaves or in sink roots with each of the measured variants; Pearson correlation coefficient test was performed.

\section{$\underline{\text { Results }}$}

Variation in chlorophyll fractions in leaves during different developmental phases

Photosynthetic activity could be elucidated by measurement the changes in chlorophyll fractions and the ratio of $\mathrm{Chl} \mathrm{b/Chl} \mathrm{a} \mathrm{ratio.} \mathrm{Results} \mathrm{in} \mathrm{Table} 1$ showed a significant increase in $\mathrm{Chl}$ a from 7.36 at $135 \mathrm{DAS}$ to $8.15 \mathrm{mg} \cdot \mathrm{g}^{-1} \mathrm{FM}$ at $165 \mathrm{DAS}$ then a significant decrease in $\mathrm{Chl}$ a concentration at 180DAS harvest reached to $77.4 \%$ of the $\mathrm{Chl}$ a content at the first selected stage. Non-significant changes in $\mathrm{Chl} b$ at selected stages were noticed except at 180 DAS harvest, a significant decrease about $54.2 \%$ of the $\mathrm{Chl} b$ content at $135 \mathrm{DAS}$ was recorded. As noticeably; $\mathrm{Chl} \mathrm{a}+\mathrm{Chl} b$ as well as $\mathrm{Chl} \mathrm{b/Chl} \mathrm{a} \mathrm{ratio} \mathrm{have} \mathrm{the} \mathrm{same} \mathrm{trend} \mathrm{of} \mathrm{Chl} \mathrm{b}$. The maximum $\mathrm{Chl}$ a $+\mathrm{Chl} \mathrm{b}$ content $\left(13.11 \mathrm{mg} \mathrm{g}^{-1}\right.$ FM) was recorded in 150d-old leaves.

Variation in sucrose and reducing sugars levels in leaves and roots during different developmental phases

Sucrose levels in both source leaves and sink roots showed a reverse trend (Table 2). Sucrose level decreased significantly in leaves from 9.08 at the first selected harvest to $2.97 \mathrm{mg} \cdot \mathrm{g}^{-1} \mathrm{FM}$ (about $32.7 \%$ ) at the last selected harvest. On the contrary, sucrose accumulation in roots increased rapidly during the first three harvest phases under this study but decreased finally at 180DAS. However, root sucrose content at 165DAS harvest rose up to $142.38 \%$ of the sucrose content at $135 \mathrm{DAS}$ harvest.

\begin{tabular}{|c|c|c|c|c|}
\hline \multirow{2}{*}{ Harvest Date } & \multicolumn{4}{|c|}{ Chlorophyll fractions mg.g ${ }^{-1}$ FM) } \\
\hline & Chl a & Chl b & Chl b/ Chl a & Chl a + Chl b \\
\hline 135DAS & $7.36 \pm 0.18^{\mathrm{b}}$ & $4.37 \pm 0.17^{\mathrm{a}}$ & $0.59^{\mathrm{c}}$ & $11.96 \pm 0.34^{\mathrm{c}}$ \\
\hline 150DAS & $7.87 \pm 0.24 \mathrm{~b}^{\mathrm{a}}$ & $5.24 \pm 0.48^{\mathrm{a}}$ & $0.67^{\mathrm{c}}$ & $13.11 \pm 0.71^{\mathrm{c}}$ \\
\hline 165DAS & $8.15 \pm 0.11^{\mathrm{a}}$ & $4.36 \pm 0.43^{\mathrm{a}}$ & $0.54^{\mathrm{ac}}$ & $12.51 \pm 0.54^{\mathrm{c}}$ \\
\hline 180DAS & $5.70 \pm 0.17^{\mathrm{c}}$ & $2.37 \pm 0.19^{\mathrm{d}}$ & $0.42^{\mathrm{a}}$ & $8.07 \pm 0.36^{\mathrm{a}}$ \\
\hline
\end{tabular}

Values are means \pm SE $(n=3)$. Superscript values with different letters in the same column are significantly different at $\mathrm{P} \leq 0.05$, LSD test. 
TABLE 2. Changes in sucrose (Suc) and reducing sugars (Red sugars) levels in leaves and roots of sugar beet plants during different developmental phases.

\begin{tabular}{|c|c|c|c|c|c|c|}
\hline \multirow{3}{*}{$\begin{array}{l}\text { Harvest } \\
\text { Date }\end{array}$} & \multicolumn{6}{|c|}{ Sugars (mg.g ${ }^{-1}$ FM) } \\
\hline & \multicolumn{2}{|c|}{ Suc } & \multicolumn{2}{|c|}{ Red sugars } & \multicolumn{2}{|c|}{ Suc/Red sugars } \\
\hline & Leaves & Roots & Leaves & Roots & Leaves & Roots \\
\hline 135DAS & $9.08 \pm 0.09^{\mathrm{d}}$ & $76.46 \pm 1.20^{\mathrm{c}}$ & $0.62 \pm 0.02^{\mathrm{d}}$ & $0.61 \pm 0.06^{\mathrm{b}}$ & $14.66 \pm 1.20^{\mathrm{b}}$ & $125.31 \pm 12.4^{\mathrm{c}}$ \\
\hline 150DAS & $5.47 \pm 0.68^{b}$ & $88.59 \pm 3.71^{\mathrm{a}}$ & $0.67 \pm 0.03^{\mathrm{d}}$ & $1.40 \pm 0.08^{c}$ & $8.20 \pm 1.01^{\mathrm{c}}$ & $63.26 \pm .7 .8^{\mathrm{a}}$ \\
\hline 165DAS & $2.97 \pm 0.21^{\mathrm{a}}$ & $108.86 \pm 1.34^{\mathrm{d}}$ & $1.06 \pm 0.05^{\mathrm{a}}$ & $2.28 \pm 0.06^{\mathrm{d}}$ & $2.80 \pm 0.14^{\mathrm{a}}$ & $47.88 \pm .3 .8^{\text {ad }}$ \\
\hline 180DAS & $2.67 \pm 0.84^{\mathrm{a}}$ & $81.22 \pm 5.69^{\mathrm{ac}}$ & $0.46 \pm 0.02^{\mathrm{c}}$ & $2.97 \pm 0.26^{\mathrm{a}}$ & $5.71 \pm 0.89^{\mathrm{f}}$ & $27.32 \pm 2.1^{\mathrm{d}}$ \\
\hline
\end{tabular}

Values are means $\pm S E(n=3)$. Superscript values with different letters in the same column are significantly different at $\mathrm{P} \leq 0.05$, LSD test.

Reducing sugars displayed the same trend in both leaves and roots except at last selected harvest (Table 2). The greatest significant increases in reducing sugars were about $171 \%$ at $165 \mathrm{DAS}$ harvested-leaves and $487 \%$ at 180 DAS harvestedroots compared to the corresponding at 135DAS harvest. It was clarified that increase in reducing sugars levels in roots was higher than in leaves. Determination of sucrose/reducing sugars ratio revealed a substantial decrease in each of leaves and roots by progressing harvest date (Table 2). It decreased significantly from 14.66 at $135 \mathrm{DAS}$ to 2.80 at 165DAS harvested-leaves and from 128.31 at $135 \mathrm{DAS}$ to 27.32 at $180 \mathrm{DAS}$ harvestedroots. The highest reducing sugars accompanied with the lowest sucrose/reducing ratio in 165DAS harvested-leaves coupled with the highest sucrose accumulation in roots was observed.
Variation in $P_{i}$ levels in leaves and roots during different developmental phases

$\mathrm{P}_{\mathrm{i}}$ levels in leaves and roots showed opposite patterns during selected harvest phases except at last one (Fig. 1). $\mathrm{P}_{\mathrm{i}}$ level in leaves decreased gradually by harvest date progress and eventually reached at $180 \mathrm{DAS}$ to $31.59 \%$ of the content at the first selected harvest. Surprisingly; levels of $\mathrm{P}_{i}$ and sucrose patterns were parallel in each of leaves and roots. On contrast to leaves, $\mathrm{P}_{\mathrm{i}}$ level increased significantly in roots by progressing harvest date to be at $165 \mathrm{DAS}$ about $175 \%$ of the content at 135DAS harvest. However; the $\mathrm{P}_{\mathrm{i}}$ level decreased at 180DAS again. But; it was pronounced that $\mathrm{P}_{\mathrm{i}}$ concentration was higher in leaves than in roots during all harvest phases under study.

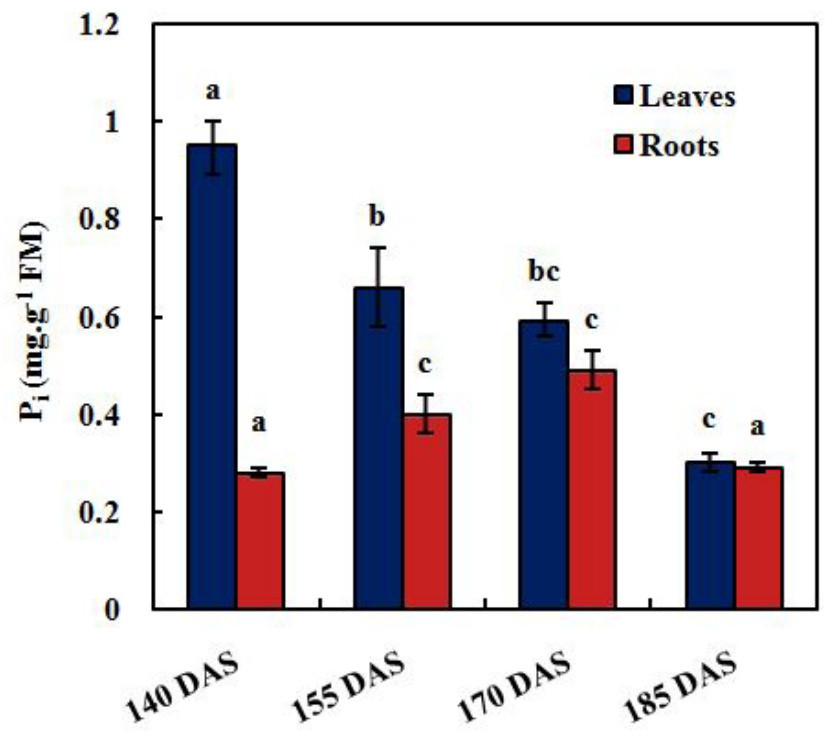

Fig. 1. Changes in Pi levels in leaves and roots of sugar beet plants during different developmental phases. Values are means $\pm S E(n=3)$. Different letters indicate a significant variance at $P \leq 0.05$, LSD test. 


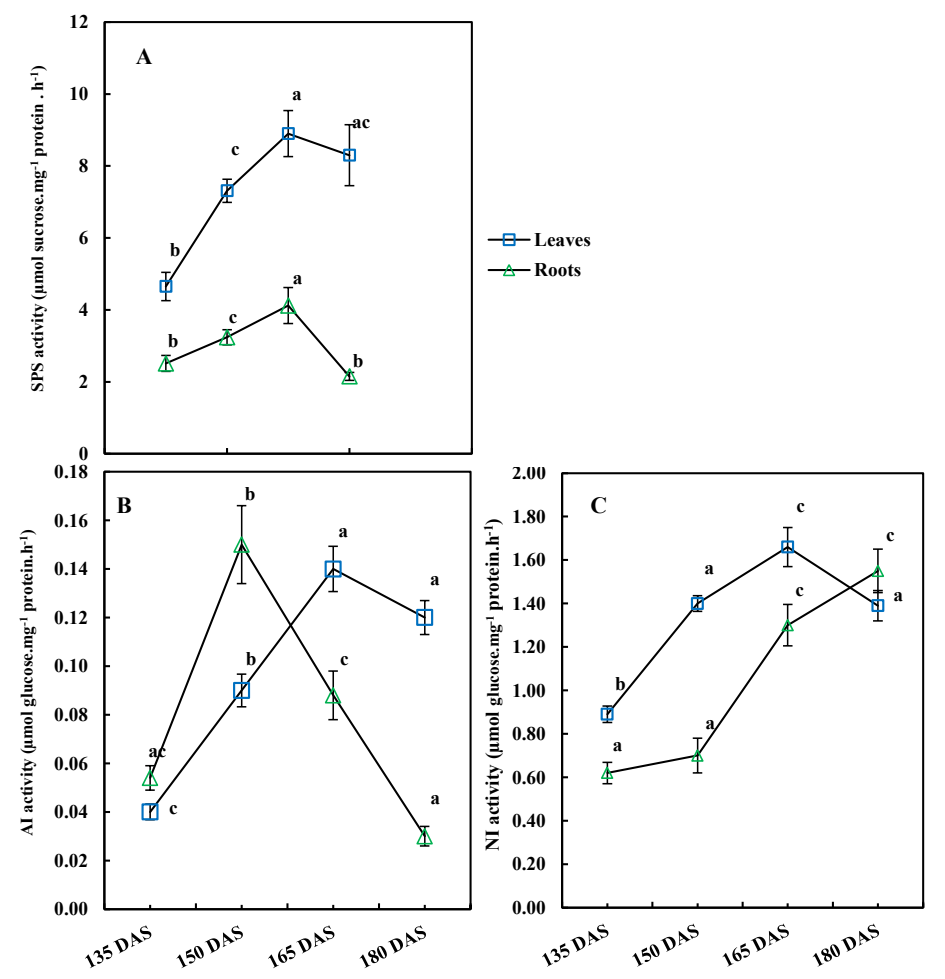

Fig. 2. Changes in activity of sucrose metabolism enzymes: A, SPS; B, AI and C, NI in leaves and roots of sugar beet plants during different developmental phases. Values are means $\pm S E(n=3)$. Different letters indicate a significant variance at $\mathbf{P} \leq 0.05$, LSD test.

Variation in activity of sucrose metabolizing enzymes in leaves and roots during different developmental phases

Because of a net activities of SPS (biosynthetic activity), and AI and NI (sucrolytic activity) enzymes could determine sucrose accumulation statue in sink roots, their activities were investigated in both leaves and roots of sugar beet plants. Investigation of SPS activity revealed similar significant increase trend in each of leaves and roots by age progress from 135 to 165 d-old and then decreased at 180DAS harvest (Fig. 2A). The activity of SPS was consistent with the sucrose accumulation in sink roots. The maximum SPS activity in leaves and roots at 165DAS reached to about $191 \%$ and $164 \%$ of the corresponding activity at 135 DAS harvest, respectively. It was clearly that SPS activity much greater in leaves than in roots during all selected harvest phases.

In leaves, AI and NI activities increased significantly during the first three selected stages then decreased non-significantly in 180DAS harvest (Fig. 2B and C). In roots; $\mathrm{AI}$ and NI activities varied greatly where a substantial descent in AI activity at last harvest reached to
$60 \%$ of the activity at $135 \mathrm{DAS}$ harvest. But, the highest significant increase in NI activity was at last harvest up to $250 \%$ of activity in $135 \mathrm{DAS}$ harvested-roots.

Correlations between sucrose accumulation and activity of sucrose metabolism enzymes, reducing sugars and chlorophylls.

Pearson correlation coefficient test was conducted between sucrose yield and each of reducing sugars, sucrose/reducing sugars ratio, total chlorophylls, Chl b/Chl a ratio, activities of SPS, $\mathrm{AI}$ and $\mathrm{NI}$ and $\mathrm{P}_{\mathrm{i}}$ level in leaves (Table 3A) and in roots (Table $3 \mathrm{~B}$ ) to identify the key regulators for sucrose accumulation. A significant positive correlation between foliar sucrose content and each of sucrose/reducing sugars ratio and $\mathrm{P}_{i}$ level ( $r=0.958,0.828$, respectively), but strong negative correlation with the activity of each of SPS, AI and NI ( $r=-0.906,-0.915,-0.876$, respectively) were found. SPS activity in leaves correlated positively with AI and NI activities $(\mathrm{P}<0.01)$ but, a significant negatively correlation with sucrose/ reducing sugars ratio $(\mathrm{P}<0.01)$ and $\mathrm{P}_{\mathrm{i}}$ level $(\mathrm{P}<0.05)$ was found, respectively. AI activity; a significant correlation between 
AI activity and each of NI activity $(\mathrm{P}<0.01)$, sucrose/reducing sugars ratio $(\mathrm{P}<0.01)$ and $\mathrm{P}_{i}$ concentration $(\mathrm{P}<0.05)$. Contrary to SPS and AI; NI activity was found to be correlated positively with reducing sugars ( $r=0.540$; non significantly) but it negatively correlated with foliar $\mathrm{P}_{\mathrm{i}}$ level $(\mathrm{P}<0.05)$. However; all investigated enzymes rather than sucrose/reducing sugars ratio coincide not to correlate with each of total chlorophylls and $\mathrm{Chl} \mathrm{b} / \mathrm{Chl}$ a ratio.

Contrary to leaves; sucrose accumulation in roots correlated positively with the activity of SPS and $\mathrm{P}_{\mathrm{i}}(\mathrm{P}<0.01)$, and non-significantly correlated with each of AI and NI (Table 3B). Also; a significant positive correlation between SPS and each of $\mathrm{P}_{\mathrm{i}}(\mathrm{P}<0.05)$ and $\mathrm{AI}$ activity $(r=0.506$; non significantly). Contrary to foliar AI activity, root AI activity not to correlate with sucrose/reducing sugars ratio. Similar to leaves, NI activity in roots highly positively correlated with reducing sugar $(\mathrm{P}<0.01)$ and negatively with sucrose/reducing sugars ratio $(\mathrm{P}<0.01)$ that might be presumed the regulatory role for NI in sucrose cycling and accumulation in sink tissue specifically during a decline in AI activity.

\section{Discussion}

In this study, an increase in Chl a by harvest date progress up to 165 DAS was detected. On the other hand, $\mathrm{Chl} b$ showed a maximum increase at 150DAS harvest associated with the highest total chlorophylls (Chl a $+\mathrm{Chl} \mathrm{b})$ as well as $\mathrm{Chl} \mathrm{b/Chl} \mathrm{a}$ ratio (Table 1). However, Rochalska (2005) found a significant increase in chlorophyll contents with growth progressing of sugar beet plants up to 100d-old that contrary to the present findings, but a pronounced increase up to $120 \mathrm{~d}$-old coupled with intensive $\mathrm{CO}_{2}$ assimilation and other metabolic processes at $120 \mathrm{DAS}$ was recorded by Rudnicki et al. (1993).

Results in Table 2 showed a gradual decrease in sucrose levels in leaves with harvest date progress. In contrary, an increase in sucrose accumulation in roots up to third selected harvest followed by a decrease in last selected harvest phase. The level of sucrose accumulation in roots was parallel to $\mathrm{Chl}$ a concentration and reducing sugars content in leaves. These findings could be considered sucrose level in source leaves a key regulator of prior synthesis rate and degradation as well as the leaf sucrose export (Sinha \& Roitsch, 2002 and Endler et al., 2006). Surprisingly, the highest reducing sugars accompanied with the lowest sucrose/ reducing ratio in 165DAS harvested-leaves coupled with the highest sucrose accumulation in roots might be indicated a regulatory role of sucrose/reducing sugars ratio in sucrose accumulation. In this respect, Suojala (2000) found an increase in sucrose to glucose and fructose ratio with carrot aging affecting by either of cultivar type and environmental conditions. In addition, Sekoli et al. (2016) reported that a decline in metabolic activities led to a decrease in conversion of sucrose into monosaccharide that might increase sucrose accumulation in tap roots. The present findings could be attributed to alteration in sucrose metabolism enzymes resulting in modification sucrose partitioning.

TABLE 3A. Correlation between sucrose level and each of the measured variants in source leaves of sugar beet plants.

\begin{tabular}{lcccccccc}
\hline Variants & Suc & Red sugars & $\begin{array}{c}\text { Suc/Red } \\
\text { sugars }\end{array}$ & $\begin{array}{c}\text { Total } \\
\text { Chl }\end{array}$ & $\begin{array}{c}\text { Chl b/ } \\
\text { Chl a }\end{array}$ & SPS & AI & NI \\
\hline Red sugars & -0.212 & & & & & & & \\
Suc/Red & $0.958^{* *}$ & -0.472 & & & & & & \\
sugars & 0.393 & 0.576 & 0.157 & & & & & \\
Total Chl & 0.518 & 0.194 & 0.386 & $0.753^{* *}$ & & & & \\
Chl b/Chl a & $-0.906^{* *}$ & 0.398 & $-0.931^{* *}$ & -0.206 & -0.336 & & & \\
SPS & $-0.915^{* *}$ & 0.455 & $-0.941^{* *}$ & -0.278 & -0.408 & $0.959^{* *}$ & \\
AI & $-0.876^{* *}$ & 0.540 & $-0.950^{* *}$ & -0.009 & -0.210 & $0.904^{* *}$ & $0.922^{* *}$ & \\
NI & $0.828^{* *}$ & 0.117 & 0.715 & 0.422 & 0.269 & $-0.685^{*}$ & $-0.624^{*}$ & $-0.597^{*}$ \\
$\mathrm{P}_{\mathrm{i}}$ & & & & & & & \\
\hline
\end{tabular}

${ }^{*_{*}}$ Correlation is significant at the 0.01 level (2-tailed).

* Correlation is significant at the 0.05 level (2-tailed). 
TABLE 3B. Correlation between sucrose level and each of the measured variants in sink roots of sugar beet plants.

\begin{tabular}{|c|c|c|c|c|c|c|}
\hline Variants & Suc & Red sugars & $\begin{array}{c}\text { Suc/Red } \\
\text { sugars }\end{array}$ & SPS & AI & NI \\
\hline Red sugars & 0.295 & & & & & \\
\hline Suc/ Red sugars & -0.357 & $-0.920^{* *}$ & & & & \\
\hline SPS & $0.806^{* *}$ & -0.010 & -0.171 & & & \\
\hline AI & 0.389 & -0.270 & -0.009 & 0.506 & & \\
\hline NI & 0.296 & $0.921^{* *}$ & $-0.753^{* *}$ & -0.101 & -0.439 & \\
\hline$P_{i}$ & $0.716^{* *}$ & 0.075 & -0.096 & $0.649^{*}$ & 0.370 & 0.065 \\
\hline
\end{tabular}

** Correlation is significant at the 0.01 level (2-tailed).

* Correlation is significant at the 0.05 level (2-tailed).

In this study, a gradual decline in $\mathrm{P}_{\mathrm{i}}$ content parallel to sucrose trend in leaves during the four selected harvest phases was observed. According to Hermans et al. (2006), this could be attributed to a decline in activities of both ATP synthase in thylakoid and ribulose-1, 5-phosphate carboxylase that led to a reduction of carbon assimilation but accompanied by increase in relocation of carbon to sink roots. In contrast, Müller et al. (2007) recorded an increase in sucrose level in P-deficient Arabidopsis leaves. Similar to the behavior of foliar $\mathrm{P}_{\mathrm{i}}$, root $\mathrm{P}_{\mathrm{i}}$ content was associated with sucrose accumulation where a gradual increase in $\mathrm{P}_{\mathrm{i}}$ content up to 165 DAS harvest followed by a decrease at the last selected harvest. Earlier; Müller et al. (2007) showed differential patterns in sucrose transcription along with modification of carbohydrate transporters in response to different $\mathrm{P}$ levels in both shoots and leaves.

However, SPS activity in each of leaves and roots showed similar trend where the maximum activity was achieved at 165DAS harvest that consistent with the greatest sucrose accumulation in roots (Fig. 2A). In agreement, Tateishi et al. (2004) stated that accumulation of sucrose during maturation of kiwi fruits was coinciding with an increase in SPS activity. In this study; results of foliar SPS activity altogether with the total chlorophyll content decreased at the last harvest that coincides with previous finding by Sakalo \& Kurchii (2004).

Activity of invertases regulates plant development by controlling sugar composition, provide growing tissues with energy (hexoses form), partition sucrose between source and sink tissues, facilitate sucrose transport and sucrose: hexose ratios related to sugar signaling (Moscatello et al., 2011). In this study, both of
AI and NI activities in leaves showed a similar trend as the maximum activity was established at 165DAS harvested-leaves consistent with the lowest sucrose/reducing sugars ratio in sucrose source leaves and highest sucrose accumulation in sucrose sink roots. Beside the differential behavior of AI and NI activities in roots was observed, it was noticeably that NI activity was much higher than AI activity during all selected stages in either leaves or roots. The maximum AI activity was at 150DAS harvest. However; a gradual increase in NI activity in roots by progress in harvest date resulting in an increase of reducing sugars content followed by a decrease in sucrose/reducing sugars ratio. These findings might indicate that NI activity is the key regulator in sucrose accumulation by controlling the sucrose degradation and production of hexoses substrates for metabolic processes. In this respect, Rossouw et al. (2010) stated that down regulation of NI induced sucrose accumulation in sugarcane transgenic lines but it was accompanied with a decline in plant vigor which is a bad event. Godt \& Roitsch (2006) found a highly decrease in AI activity in sink tissue of sugar beet accompanied with sucrose accumulation. Similarly; evanescence of AI activity during maturation of melon fruit accompanied with loss in AI protein and unaffected with AI protein inhibitors revealed that loss in AI activity in sucrose accumulating tissues might be traced back to molecular regulation specifically at transcriptional stage (Lester et al., 2001 and Miron et al., 2001).

In the present study, foliar sucrose content strongly correlated negatively with activities of sucrose metabolism enzymes under study (SPS, $\mathrm{AI}$ and NI) and positively with sucrose/reducing ratio as well as with $\mathrm{P}_{\mathrm{i}}$ content. Also, sucrose was non-significantly correlated positively 
with $\mathrm{Chl} \mathrm{b} / \mathrm{Chl}$ a ratio and uncorrelated with reducing sugars and total chlorophylls. On the other hand, root sucrose accumulation strongly correlated positively with SPS and $\mathrm{P}_{i}$ content (Table 3A and B). Similarly, McCormick et al. (2008) found a weakly relation of sucrose content with photosynthetic activity that might be assumed the feedback regulation of photosynthesis by sucrose beside hexoses levels. However; SPS activity induction would promote carbon assimilation as well as source to sink relationships (Baxter et al., 2003). Botha \& Black (2000) considered the negative correlation of AI activity with sucrose content is essential for sucrose accumulation.

Surprisingly, all sucrose metabolizing enzymes under this study (SPS, AI and NI) strongly correlated positively with sucrose/ reducing sugars ratio and with each other in leaves but only NI strongly correlated with reducing sugars and sucrose/reducing sugars ratio in roots. Concurrently, Rohwer \& Botha (2001) suggested that NI has a regulatory effect on sucrose accumulation attributed to strong correlation with either of reducing sugars and total sugars levels in 360DAP sugarcane. In addition, Datir \& Joshi (2016) recorded a positive correlation between each of AI and NI activity with reducing sugars on the one hand and a negative correlation with each of total sugars and total sugars/reducing sugars ratio on the other hand. In addition; Verma et al. (2011) found that AI activity was correlated inversely with sucrose accumulation and positively with hexoses content in sugar storage tissues. Recently; a partial correlation was found between NI and each of sucrose, glucose and soluble sugars in wounded leaves of Arabidopsis thaliana rcd1 (Radical-induced cell death 1 mutant with reduced sensitivity to ABA, ethylene, and methyl jasmonate) and aos (jasmonate deficiency) mutants (Lukaszuk et al., 2017).

\section{Conclusion}

High accumulation of sucrose in sink root up to 165DAS harvest was matched with increases in SPS activity either in leaves and roots and AI and NI activity accompanied with an increase in reducing sugars and a decrease of sucrose/ reducing sugars ratio in leaves. A decrease in sucrose accumulation at 180DAS harvest was coupled with a decrease in SPS activity in both source and sink and an increase in NI activity in roots accompanied with an increase in reducing sugars that resulting in a further decrease in sucrose/reducing sugars ratio. These findings could be referred to the key regulatory role of sucrose/reducing sugars ratio in regulation of both SPS and NI activities in leaves and roots that might be determined sucrose accumulation. In support, a strong correlation of sucrose/reducing sugars ratio with SPS in leaves and with NI in both leaves and roots was found.

\section{References}

Baxter, C.J., Foyer C.H., Turner J., Rolfe, S.A. and Quick, W.P. (2003) Elevated sucrosephosphate synthase activity in transgenic tobacco sustains photosynthesis in older leaves and alters development. Journal of Experimental Botany, 54(389), 1813-1820.

Borisjuk, L., Rolletschek, H., Wobus, U. and Weber, H. (2003) Differentiation of legume cotyledons as related to metabolic gradients and assimilate transport into seeds. Journal of Experimental Botany, 54(382), 503-512.

Botha, F.C. and Black, K.G. (2000) Sucrose phosphate synthase and sucrose synthase activity during maturation of internodal tissue in sugarcane. Australian Journal of Plant Physiology, 27, 81-85.

Bradford, M.M. (1976) A rapid and sensitive method for the quantitation of microgram quantities of protein utilizing the principle of protein-dye binding. Analytical Biochemistry, 72, 248-254.

Buysse, J. and Merckx, R. (1993) An improved colorimetric method to quantify sugar content of plant tissue. Journal of Experimental Botany, 44, 1627-1629.

Chen, P.S., Toribara, T.Y. and Warner, H. (1956) Microdeterminations of phosphorus. Analytical Biochemistry, 28, 1756-1758.

Chen, W.L., Huang, D.J., Liu, P.H., Wang, H.L., $\mathrm{Su}$, J.C. and Lee, P.D. (2001) Purification and characterization of sucrose phosphate synthase from sweet potato tuberous roots. Botanical Bulletin of the Academia Sinica, 42, 123-129.

Datir, S. and Joshi, S. (2016) The contribution of sucrose metabolism enzymes to sucrose accumulation in sugarcane (Saccharum officinarum L) genotypes. 
Endler, A., Meyer, S., Schelbert, S., Schneider, T., Weschke, W., Peters, S.W., Keller, F., Baginsky, S., Martinoia, E. and Schmidt, U.G. (2006) Identification of a vacuolar sucrose transporter in barley and Arabidopsis mesophyll cells by a tonoplast proteomic approach. Plant Physiology, 141, 196-207.

Geromel, C., Ferreira, L.P., Guerreiro, S.M.C., Cavalari, A.A., Pot, D., Pereira, L.F.P., Leroy., T., Vieira, L.G.E., Mazzafera, P. and Marraccini, P. (2006) Biochemical and genomic analysis of sucrose metabolism during coffee (Coffea arabica) fruit development, Journal of Experimental Botany, 57(12), 3243-3258.

Godt, D. and Roitsch, T. (2006) The developmental and organ specific expression of sucrose cleaving enzymes in sugar beet suggests a transition between apoplasmic and symplasmic phloem unloading in the tap roots. Plant Physiology and Biochemistry, 44, 656-665.

Gupta, U.S. (2006) "Physiology of Stressed Crops: Osmoregulation and Protection", Volume IV. Science Publishers, Endfield, New Hampshire, USA.

Hermans, C., Hammond, J.P., White, P.J. and Verbruggen, N. (2006) How do plants respond to nutrient shortage by biomass allocation? Trends Plant Science, 11, 610-617.

Hess, H. and Willmitzer, L. (1996) Expression analysis of a sucrose synthase gene from sugar beet (Beta vulgaris L). Plant Molecular Biology, 30, 863-872.

Jaleel, C.A., Kishorekumar, A., Manivannan, P., Sankar, B., Gomathinayagam, M., Gopi, R., Somasundaram, R. and Panneerselvam, R. (2007) Alterations in carbohydrate metabolism and enhancement in tuber production in white yam (Dioscorea rotundata Poir.) under triadimefon and hexaconazole applications. Plant Growth Regulation, 53, 7-16.

Kutschera, U. and Heiderich, A. (2002) Sucrose metabolism and cellulose biosynthesis in sunflower hypocotyls. Physiologia Plantarum, 114, 372-379.

Lee, H.S. and Sturm, A. (1996) Purification and characterization of neutral and alkaline invertase
Lester, G.E., Arias, L.S. and Gomez-Lim, M. (2001) Muskmelon fruit soluble acid invertase and sucrose phosphate activity and polypeptide profiles during growth and maturation. Journal of American Society for Horticultural Science, 126, 33-36.

Lichtenthaler, H.K. (1987) Chlorophylls and carotenoids: Pigments of photosynthetic biomembranes. Methods in Enzymology, 148, 350-382.

Lukaszuk, E., Rys, M., Moźdźeń, K., Stawoska, I., Skoczowski, A. and Ciereszko, I. (2017) Photosynthesis and sucrose metabolism in leaves of Arabidopsis thaliana aos, ein 4 and rcd1 mutants as affected by wounding. Acta Physiologiae Plantarum, 39, 17.

McCormick, A.J., Cramer, M.D. and Watt, D.A. (2008) Changes in photosynthetic rates and gene expression of laves during a source - sink perturbation in sugarcane. Annals of Botany, 101, 89-102.

McMichael, R.W., Kochansky, J., Klein, R.R. and Huber, S.C. (1995) Characterization of the substrate specificity of sucrose-phosphate synthase protein kinase. Archives of Biochemistry and Biophysics, 321, 71-75.

Miller, G.L. (1959) Use of dinitrosalicylic acid reagent for determination of reducing sugars. Analytical Chemistry, 31(3), 426-428.

Miron, D., Petreikov, M., Carmi, N., Shen, S., Levin, L., Granot, D., Zamski, E. and Schaffer, A.A. (2001) Invertase localization, gene expression, and sucrose uptake in developing fruit of $L$. esculentum and in the sucrose-accumulating L. hirsutum. Physiologia Plantarum, 115, 35-47.

Moscatello, S., Famiani, F., Proietti, S., Farinelli, D. and Battistelli, A. (2011) Sucrose synthase dominates carbohydrate metabolism and relative growth rate in growing kiwifruit (Actinidia deliciosa, cv Hayward). Scientia Horticulturae, 128(3), 197-205.

Müller, R., Morant, M., Jarmer, H., Nilsson, L. and Nielsen, T.H. (2007) Genome-wide analysis of the Arabidopsis leaf transcriptome reveals interaction of phosphate and sugar metabolism. Plant Physiology, 143, 156-171. 
Oliveira, D.P., Oliveira, L.E.M and Filho, N.D. (2006) Optimization of invertase assay conditions in rubber tree plants (Hevea brasiliensis Muell. Arg.). Revista Árvore, 30(5), 687-692.

Rao, I.M., Arulanantham, A.R. and Terry, N. (1989) Leaf phosphate status, photosynthesis and carbon partitioning in sugar beet. II. Diurnal changes in sugar phosphates, adenylates and nicotinamide nucleotides. Plant Physiology, 90, 820-826.

Rochalska, M. (2005) Influence of low frequent magnetic field on chlorophyll content in leaves of sugar beet plants. Nukleonika, 50(2), S25-S28.

Rohwer, J. and Botha, F.C. (2001) Analysis of sucrose accumulation in the sugarcane culm on the basis of in vitro kinetic data. Biochemical Journal, 358, 437-445.

Rossouw, D., Kossmann, J., Botha, F.C. and Groenewald, J. (2010) Reduced neutral invertase activity in the culm tissues of transgenic sugarcane plants results in a decrease in respiration and sucrose cycling and an increase in the sucrose to hexose ratio. Functional Plant Biology, 37(1), 22-31.

Rudnicki, F., Wasilewski, P. and Kotwica, K. (1993) Cultivation of sugar beet. Fragmenta Agronomica, 2(38), 63-75.

Sakalo, V.D. and Kurchii, V.M. (2004) Hormonal control of sucrose phosphate synthase and sucrose synthase in sugar beet. Russian Journal of Plant Physiology, 51(2), 183-188.

Sekoli, M.M.S., Pretorius, J.C. and Coetzer, G.M. (2016) Sugar and $\beta$-carotene accumulation in carrot (Daucus carota L) tap roots as influenced by fertilization and bio-stimulant application under greenhouse conditions. Global Journal of Agricultural Research, 4(2), 18-31.

Sinha, A.K. and Roitsch, T. (2002) Effect of different sugars on photosynthesis and chlorophyll fluorescence in photoautotrophic tomato suspension cell cultures. Photosynthetica, 39(4), 611-614.

Stitt, M. and Quick, W.P. (1989) Photosynthetic carbon partitioning: Its regulation and possibilities for manipulation. Physiologia Plantarum, 77, 633-641.

Suojala, T. (2000) Variation in sugar content and composition of carrot storage roots at harvest and during storage. Scientia Horticulturae, 85(1/2), 1-19.

Tateishi, A., Nakayama, T., Isobe, K., Nomura, K., Watanabe, K. and Inoue, H. (2004) Changes in sugar metabolism enzyme activities in cultivars of two pumpkin species (Cucurbita maxima and C. moschata) during fruit development. Journal of the Japanese Society of Horticultural Science, 73, 57-59.

Ticconi, C.A., Delatorre, C.A. and Abel, S. (2001) Attenuation of phosphate starvation responses by phosphate in Arabidopsis. Plant Physiology, 127, 963-972.

Verma, A.K., Upadhyay, S.K., Srivastava, M.K., Verma, P.C., Solomon, S. and Singh, S.B. (2011) Transcript expression and soluble acid invertase activity during sucrose accumulation in sugarcane. Acta Physiologiae Plantarum, 33, 1749-1757.

Wongmetha, O., Ke, L.S. and Liang, Y.S. (2012) Sucrose metabolism and physiological changes during Mango cv. Irwin growth and development. Horticulture, Environment and Biotechnology, 53(5), 373-377.

Ye, Y., Yuan, J., Chang, X., Yang, M., Zhang, L., Lu, K. and Lian, X. (2015) The phosphate transporter gene OsPht1;4 is involved in phosphate homeostasis in rice. PLoS ONE, 10(5), e0126186.

(Receive 7 / 2/2018; accepted 23/4/2018) 
منظمات تراكم السكروز الرئيسية أثناء مراحل تظور نبات بنجر السكر المختلفة عواطف سعد على قسم النبات ـ كلية العلوم - جامعة كفر الثيخ ـ كفر الثيخ - مصر.

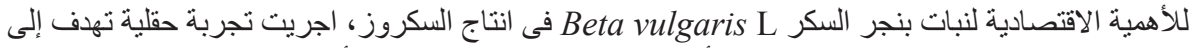

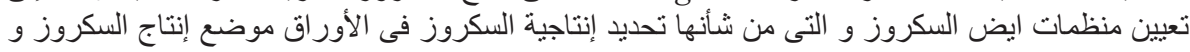

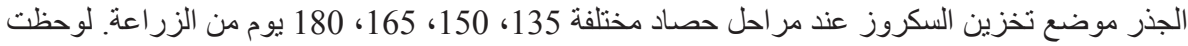

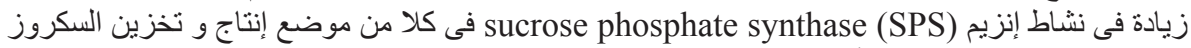

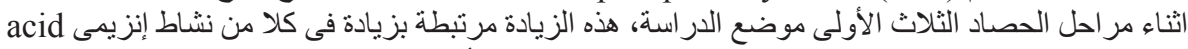
invertase (AI) and neutral invertase (NI)

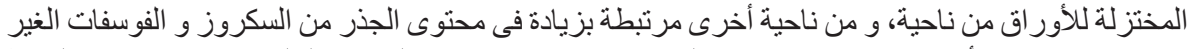

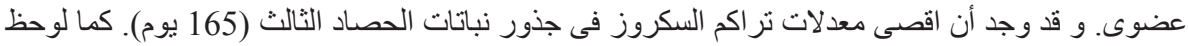

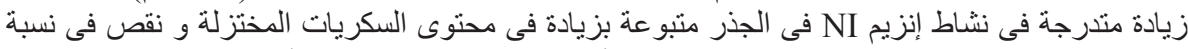

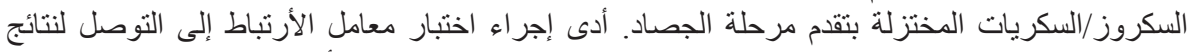

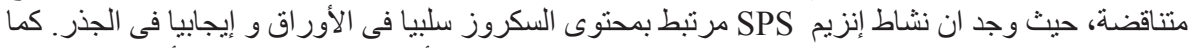

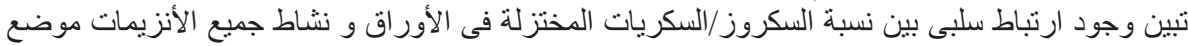

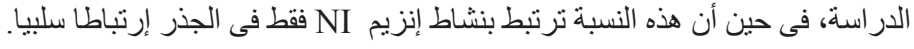

